\title{
La creación de la Sociedad por Acciones Simplificada: Análisis constitucional de este nuevo régimen en materia de Sociedades Mercantiles
}

\author{
Álvaro Ramírez Martínez* \\ Recibido: 10 febrero \\ Dictaminado: 7 de abril
}

\section{Resumen}

El pasado 14 de marzo de 2016, Enrique Peña Nieto, Presidente de los Estados Unidos Mexicanos publicó en el Diario Oficial de la Federación el decreto por medio del cual el Congreso de la Unión reformó la Ley General de Sociedades Mercantiles para crear una nueva modalidad de persona jurídica que se denomina Sociedad por Acciones Simplificada (SAS). El estado mexicano aspira a cumplir a través de este reciente estatuto con algunos estándares internacionales sugeridos por la Organización para la Cooperación y Desarrollo Económicos (OCDE). En esta novedosa sociedad mercantil se introduce entre otras cosas, la utilización de la firma electrónica avanzada como requisito indispensable para su constitución lo que significa un avance en la utilización de tecnología informática para abatir trámites burocráticos. Otra innovación interesante en este nuevo régimen societario lo constituye la privilegiación de los mecanismos alternativos de solución de controversias previstos en el Código de Comercio para sustanciar conflictos que surjan entre los accionistas, así como de éstos con terceros. Asimismo, los accionistas no requieren en la constitución de este régimen societario de la intervención de fedatarios públicos (notarios públicos, quienes dan fé pública de actos jurídicos en general ni de corredores públicos quienes otorgan fé pública a los actos jurídicos de comercio)

El Congreso de la Unión promovió esta reforma como resultado de los esfuerzos del estado mexicano para atraer Inversión Extranjera Directa (IED), a fin de establecer una sociedad mercantil sin tomar en cuenta la violación de los derechos humanos de los futuros socios

* Docente Investigador Universidad de Guadalajara luxor64_2000@yahoo.com 
o inversores, nacionales o extranjeros, ya que la constitución de una sociedad mercantil se basa en el concepto de fe pública delegada a particulares, tal y como se establece en las leyes estatales y federales. El concepto de fe pública ya ha sido definido en tesis vigentes por los órganos del Poder Judicial de la Federación.

A pesar de que México ha celebrado más de una docena de tratados de libre comercio con diversos países de diferentes bloques económicos, los inversionistas nacionales y extranjeros están en riesgo al utilizar esta modalidad de régimen mercantil en razón de la incertidumbre que existe al constituir este tipo de sociedades mercantiles, ante la ausencia de fe pública en su constitución.

Palabras clave: México, e-gobierno, Inversión Extranjera Directa, Sociedades Mercantiles, Derecho Mercantil, Tratados de Libre Comercio, Derechos Humanos

\section{The creation of the Simplified Shares Company: Constitutional analysis of this new regime in matters of Mercantile Companies}

\section{Abstract}

After six months of its publishing in Mexico's Official Journal, the bill, which creates the Shares Simplified Corporation (Sociedad por Acciones Simplificada), came into effect on September 14th, 2016 as a reform of the General Act of Mercantile Corporations (Ley General de Sociedades Mercantiles). This new scheme for corporations is inspired on the Principles for Corporate Governance issued by the Organization for Development and Economic Cooperation (OCDE) in order to reach international standards. This innovative corporation can be constituted online by one or several shareholders in 24 hours. Shareholders must bear an electronic signature in order to apply for this corporation. Furthermore, if controversies arise among shareholders, mandatorily Alternative Dispute Resolution Mechanisms (ADR's) are preferred over adjudication. Shareholders are not required to use the services of fedatarios públicos( notarios públicos and corredores públicos). Surprisingly, in implementing this new corporation system, the Mexican state set aside one of its legal cornerstones: public faith, which is vested by the state upon public notaries (notarios públicos), who give public faith on all juridical acts and upon brokers (corredores públicos), who give public faith specifically on commercial acts. Mexico's efforts to increase Foreign Direct Investment (FDI) led the Federal Legislative Power to promote this reform in order to implement a new way to constitute a business corporation without considering the violation 
of human rights of future investors, national and foreign because the constitution of business corporations lies primarily in the concept of public faith as provided in state and federal laws as well as the judiciary. Although Mexico has entered into more than a dozen free trade agreements with several countries from different economic blocs, future national and foreign direct investments are at peril due to the legal uncertainty in constituting these kinds of business corporations.

Key words: Mexico, e-government, Foreign Direct Investment, Corporations, Business Law, Free Trade Agreements, Human Rights

\section{Sumario}

I. Introducción; II. Origen de la Reforma a la Ley General de Sociedades Mercantiles que crea a la Sociedad por Acciones Simplificada; III. Reforma a la Ley General de Sociedades Mercantiles que crea a la Sociedad por Acciones Simplificada; IV. Problemas jurídicos que implica la Reforma; 4.1 Fe pública en el sistema legal mexicano; 4.2 La implementación electrónica de la Sociedad por Acciones Simplificada viola los derechos humanos de seguridad y legalidad jurídica contenidos en la Constitución Política de los Estados Unidos Mexicanos; 4.3 Violación al principio de progresividad de los derechos humanos; V Conclusiones; Bibliografía

\section{Introducción}

El pasado 14 de marzo de 2016, Enrique Peña Nieto, Presidente de los Estados Unidos Mexicanos publicó en el Diario Oficial de la Federación el decreto por medio del cual, el Congreso de la Unión reformó la Ley General de Sociedades Mercantiles $^{1}$ para crear una nueva modalidad de persona jurídica que se denomina Sociedad por Acciones Simplificada (SAS). Hay muchas expectativas entre emprendedores e inversionistas, nacionales y extranjeros sobre este nuevo régimen jurídico cuyo fin es incentivar la constitución de pequeñas y medianas empresas $^{2}$. El estado mexicano aspira cumplir a través de este reciente estatuto

1 Publicada en el Diario Oficial de la Federación (DOF) el 4 de agosto de 1934.

2 De acuerdo al artículo 16 de la Ley Federal del Trabajo vigente la empresa se define en los siguientes términos: Para los efectos de las normas de trabajo, se entiende por empresa la unidad económica de producción 
con algunos estándares internacionales sugeridos por la Organización para la Cooperación y Desarrollo Económicos (OCDE) cuyo Secretario General desde 2006 ha sido un ciudadano mexicano: Ángel Gurría.

México ha celebrado tratados internacionales con diferentes países pertenecientes a diversos bloques económicos de los 5 continentes entre acuerdos multilaterales, acuerdos de libre comercio, acuerdos marco y acuerdos comerciales preferenciales. ${ }^{3}$ Lo anterior resalta la importancia del marco jurídico que debe reglamentar la constitución y funcionamiento de las empresas pequeñas, medianas y grandes, las cuales pueden ser receptoras de inversión extranjera directa (IED) al amparo de estos instrumentos internacionales. En este país el ordenamiento que permite la constitución y operación de empresas es la Ley General de Sociedades Mercantiles que es precisamente la que se reforma para permitir este nuevo régimen de personas jurídicas dedicadas al comercio.

La Ley General de Sociedades Mercantiles (LGSM) vigente consta de catorce capítulos y doscientos setenta y tres artículos, siendo precisamente la modificación del capítulo XIV el que da origen a esta nueva forma de sociedad mercantil, la Sociedad por Acciones Simplificada también conocida en la literatura especializada como Sociedad Unimembre (Castrillón y Luna, 2010:229)4. Uno

o distribución de bienes o servicios y por establecimiento la unidad técnica que como sucursal, agencia u otra forma semejante, sea parte integrante y contribuya a la realización de los fines de la empresa.

3 En materia de Acuerdos de Libre Comercio (ALC) bilaterales y multilaterales, México forma parte de: 1. La Alianza del Pacífico, con Chile, Colombia y Perú, 2. ALC con Centroamérica (Costa Rica, El Salvador, Guatemala Honduras y Nicaragua), 3. Perú (ACE 67), 4. Bolivia (ACE 66), 5. Japón, 5. Panamá, 7. Uruguay (ACE 66), 8. Asociación Europea de Libre comercio (AELC), 9. Israel, 10. Chile (ACE 41), 11. Unión Europea (EU), 12. Colombia, 13. Tratado de Libre Comercio de América del Norte: Canadá, México y Estados Unidos (TLCAN), Acuerdos marco: 14. MERCOSUR (ACE N. 54). Acuerdos Comerciales preferenciales: 15. Argentina (ACE No. 6), 16. MERCOSUR (ACE No.55) acuerdo sobre sector automotor, 16. Brasil (AAP.CE No. 53), 17. Brasil (AAP.R 38), Panamá (AAP.A.25TM No. 14), 18. Ecuador (AAP 29). Acuerdos Comerciales suscritos aún no vigentes: 19. Acuerdo de Asociación Transpacífico: Canadá Estados Unidos, México, Perú, Chile, Nueva Zelandia, Australia, Japón, Malasia, Brunei, Singapur y Vietnam.

4 Sociedad unimembre, de un solo socio, one man Company en el derecho inglés, einmenschgesellschaft del alemán, es el ente jurídico de carácter empresarial, que mediante la separación de un determinado porcentaje de su patrimonio, que se destina a la realización de actividades mercantiles, tiene como finalidad la ejecución de actividades comerciales de manera equivalente a la organización que realizaría la corporación con pluralidad de socios, y puede tener el carácter permanente o bien temporal, solamente limitado al tiempo necesario para el restablecimiento del número de socios exigido por la normatividad o para su necesaria liquidación en el caso de que por así establecerlo la ley, no se logre la pluralidad requerida. 
de los obstáculos más evidentes para constituir pequeñas y medianas empresas en México es el tiempo excesivo que tienen que invertir los emprendedores en la formalización de cualquiera de las seis modalidades de sociedades mercantiles que contemplaba la ley de la materia, ${ }^{5}$ previo a su reforma.

En esta novedosa sociedad mercantil se introduce entre otras cosas, la utilización de la firma electrónica avanzada como requisito indispensable para su constitución lo que significa un avance en la utilización de tecnología informática para abatir trámites burocráticos. Otra innovación interesante en este nuevo régimen societario lo constituye la privilegiación de los mecanismos alternativos de solución de controversias previstos en el Código de Comercio ${ }^{6}$ para sustanciar conflictos que surjan entre los accionistas, así como de éstos con terceros. Estos mecanismos alternativos se contemplan ya en la Constitución Política de los Estados Unidos Mexicanos en el artículo 17 de la carta magna a partir de la reforma de fecha 18 de junio de 2008. ${ }^{7}$. En esta nueva modalidad societaria, diferentes dependencias de la Administración Pública Federal como la Secretaría de Hacienda y Crédito Público y la Secretaría de Economía juegan un papel crucial en la constitución y operación de la Sociedad por Acciones Simplificada.

Bajo esta perspectiva, en este artículo me referiré inicialmente al origen de la reforma, explicaré la reforma a la LGSM que crea a la Sociedad por Acciones Simplificada, así como sus peculiaridades y los problemas jurídicos que presenta. Abordaré específicamente el concepto de fe pública en el sistema legal mexicano y el papel crucial que juegan los depositarios de la misma en la relación entre particulares que son los fedatarios públicos: notarios públicos y corredores públicos según los criterios emitidos por el Poder Judicial de la

5 Ley General de Sociedades Mercantiles: Artículo 1.- Esta Ley reconoce las siguientes especies de sociedades mercantiles: I.- Sociedad en nombre colectivo; II.- Sociedad en comandita simple; III.- Sociedad de responsabilidad limitada; IV.- Sociedad anónima; V. Sociedad en comandita por acciones; VI. Sociedad cooperativa.

6 Libro Quinto del Código de Comercio de los Estados Unidos Mexicanos: Artículo 1051, primer párrafo: El procedimiento mercantil preferente a todos es el que libremente convengan las partes con las limitaciones que se señalan en este libro, pudiendo ser un procedimiento convencional ante Tribunales o un procedimiento arbitral.

7 Cuarto párrafo del artículo 17 constitucional: Las leyes preverán mecanismos alternativos de solución de controversias. En la materia penal regularán su aplicación, asegurarán la reparación del daño y establecerán los casos en los que se requerirá supervisión judicial. 
Federación. Posteriormente señalo cómo la implementación electrónica de este nuevo régimen societario viola los derechos humanos de seguridad y legalidad jurídica amparados en la constitución mexicana y atenta contra el principio de progresividad establecido en la carta magna. Finalmente, expreso conclusiones sobre este artículo.

\section{Origen de la Reforma a la Ley General de Sociedades Mercantiles que crea a la Sociedad por Acciones Simplificada}

En la Exposición de motivos de la reforma a la LGSM que crea en México la Sociedad por Acciones Simplificada se explica que su génesis se encuentra en los principios $^{8}$ de gobierno corporativo publicados por la OCDE en $1999 \mathrm{y}$ revisados en 2004. Estos principios representan un importante instrumento que ofrece normas no obligatorias y buenas prácticas, así como una guía para su implementación, susceptible de ser adaptada a las circunstancias particulares de cada país o región. La citada exposición de motivos también señala que la estructura económica de los países muestra que las micro, pequeñas y medianas empresas (Mipyme) son la columna vertebral y el motor de las economías, por su contribución al empleo, como su aportación al producto interno bruto (PIB). En el caso de México, éste cuenta con una estructura empresarial fundada casi principalmente en Mipymes y que representan más de 4 millones de empresas, de las cuales 99.8 por ciento son Mipymes que generan 52 por ciento del PIB y 72 por ciento del empleo en el país.

Sólo existe una legislación en México que se refiere específicamente a la micro, pequeña y mediana empresa, que es la Ley para el Desarrollo de la Competitividad de la Micro, Pequeña y Mediana Empresa, pero su objeto específico atento al artículo 1 de esa ley es: "promover el desarrollo económico

$8 \mathrm{Su}$ revisión se fundamentó en un extenso estudio sobre cómo los países miembros de esta organización enfrentaban los distintos desafíos que se les planteaban en materia de gobierno corporativo y además en economías de países no integradas a la OCDE. 
nacional a través del fomento a la creación de micro, pequeñas y medianas empresas y el apoyo para su viabilidad, productividad, competitividad y sustentabilidad. Asimismo, incrementar su participación en los mercados, en un marco de crecientes encadenamientos productivos que generen mayor valor agregado nacional. Lo anterior, con la finalidad de fomentar el empleo y el bienestar social y económico de todos los participantes en la micro, pequeña y mediana empresa." No obstante esta normatividad, la misma no establece el marco legal para constituir y operar mipymes, por lo que el único sustento jurídico para la creación y funcionamiento de éstas, se encuentra precisamente en la Ley General de Sociedades Mercantiles.

La multicitada exposición de motivos proclama que esta nueva persona jurídica dedicada al comercio se alinea con los principios y mejores prácticas de un gobierno corporativo, donde se establece un balance y un contrapeso efectivo entre las funciones de administración, dirección y vigilancia, que están en concordancia con los preceptos tradicionalmente contenidos en la legislación mercantil mexicana.

\section{Reforma a la Ley General de Sociedades Mercantiles que crea a la Sociedad por Acciones Simplificada}

La reforma a la Ley General de Sociedades Mercantiles (LGSM) publicada en el Diario Oficial de la Federación del 14 de marzo de 2016 actualiza el párrafo segundo del artículo $1^{\circ}$.; el párrafo primero del artículo 20; la denominación del Capítulo XIV para quedar como "De la sociedad por acciones simplificada", los artículos 260, 261, 262, 263 y 264; se adicionan una fracción VII al artículo $1^{\circ}$.; un párrafo quinto al artículo $2^{\circ}$., y se recorren los subsecuentes; un segundo párrafo al artículo 5o.; los artículos 265, 266, 267, 268, 269, 270, 271, 272 у 273 de la Ley General de Sociedades Mercantiles.

El articulado en la citada ley que crea la Sociedad por Acciones Simplificada (SAS) está estructurado de la siguiente manera:

(a) Definición y restricciones a los socios (b) Tope de ingresos y 
transformación (c) Denominación (d) Requisitos (e) Procedimiento de constitución (f) Estatutos Sociales (g) Responsabilidad de los socios por comisión de delitos (h) Inscripción de contratos (i) Pago de Acciones (j) Inscripción de contratos (k) Asamblea de Accionistas (l) Representación de la Sociedad (m) Administrador de la Sociedad y facultades (n) Toma de decisiones de la Asamblea de Accionistas (o) Convocatoria de Asamblea de Accionistas (p) Validez de la Asamblea de Accionistas (q) Modificación de los Estatutos Sociales (r) Modificación, organización y transformación de la Sociedad (s) Mecanismos Alternos de Solución de Controversias (t) Utilidades (u) Publicación Informe anual (v) Disolución forzada de la Sociedad y Declaratoria de Incumplimiento (w) Supletoriedad de la ley (x) Accionista único

La sociedad por acciones simplificada es aquella que se constituye con una o más personas físicas que solamente están obligadas al pago de sus aportaciones representadas en acciones ${ }^{9}$. Esto significa que los accionistas sólo están obligados a responder por las obligaciones que contraiga la sociedad de manera individual, por el monto de cada una de sus acciones que constituyen el capital social. El patrimonio y la personalidad de la sociedad están separados del patrimonio y la personalidad de los accionistas, tal y como lo ha reiterado recientemente el Poder Judicial de la Federación tanto en una tesis aislada en materia civi1 ${ }^{10}$ como en una jurisprudencia en materia administrativa ${ }^{11}$ al explicar en materia de sociedades mercantiles, en qué consiste la técnica del velo corporativo y cómo se aplica.

Los requisitos principales ${ }^{12}$ para constituir este régimen mercantil son:

9 Artículo 260 de la Ley General de Sociedades Mercantiles.

10 VELO CORPORATIVO. ES UNA GARANTÍA PARA LA PROTECCIÓN DE LOS ÁMBITOS INTERNO Y EXTERNO DE UNA SOCIEDAD MERCANTIL, QUE CONTRIBUYE AL PRINCIPIO DE SEPARACIÓN DE PERSONALIDADES.

11 TÉCNICA DEL "LEVANTAMIENTO DEL VELO DE LA PERSONA JURÍDICA O VELO CORPORATIVO". SU SUSTENTO DOCTRINAL Y LA JUSTIFICACIÓN DE SU APLICACIÓN EN EL PROCEDIMIENTO DE INVESTIGACIÓN DE PRÁCTICAS MONOPÓLICAS.

12 Artículo 262.- Para proceder a la constitución de una sociedad por acciones simplificada únicamente se requerirá: I. Que haya uno o más accionistas; II. Que el o los accionistas externen su consentimiento para constituir una sociedad por acciones simplificada bajo los estatutos sociales que la Secretaría de Economía ponga a disposición mediante el sistema electrónico de constitución; III. Que alguno de los accionistas cuente con la autorización para el uso de denominación emitida por la Secretaría de Economía, y IV. Que todos los accionistas cuenten con certificado de firma electrónica avanzada vigente reconocido en las reglas generales que emita la Secretaría de Economía conforme a lo dispuesto en el artículo 263 de esta Ley. En ningún caso se 
a. Que haya uno o más accionistas y b. Que todos los accionistas cuenten con certificado de firma electrónica avanzada ${ }^{13}$ vigente, lo que constituye una novedad en la utilización de las tecnologías de la información y comunicación (TIC's). El uso de estas tecnologías (Gil-García, Mariscal, Ramírez, 2008) establece una nueva era en la implementación del e-gobierno ${ }^{14}$ en México $^{15}$ a través de la simplificación administrativa. Otro requisito para establecer esta sociedad mercantil es que alguno de los accionistas cuente con la autorización para el uso de la denominación ${ }^{16}$ emitida por la Secretaría de Economía, denominación que irá siempre seguida de las palabras Sociedad por Acciones Simplificada o de su abreviatura "SAS". Este ordenamiento establece claramente que en ningún caso se exigirá el requisito de escritura pública, ${ }^{17}$ póliza $^{18}$ o cualquier otra formalidad adicional, para la constitución de la sociedad por acciones simplificada. ${ }^{19}$

La no intervención de fedatarios público ${ }^{20}$ por disposición expresa de la ley para la constitución de este régimen societario establece un nuevo paradigma que

exigirá el requisito de escritura pública, póliza o cualquier otra formalidad adicional, para la constitución de la sociedad por acciones simplificada.

13 La Ley de Firma Electrónica Avanzada en su artículo 2 fracción XIII define la misma así: Firma Electrónica Avanzada: el conjunto de datos y caracteres que permite la identificación del firmante, que ha sido creada por medios electrónicos bajo su exclusivo control, de manera que está vinculada únicamente al mismo y a los datos a los que se refiere, lo que permite que sea detectable cualquier modificación ulterior de éstos, la cual produce los mismos efectos jurídicos que la firma autógrafa.

14 Gobierno electrónico en México.

15 Una de las aplicaciones más importantes que han ofrecido las tecnologías de información y comunicación (TIC's) es la posibilidad de modernizar la gestión pública a través de su uso para la prestación de servicios, el mejoramiento de la operación interna y el fortalecimiento de sus relaciones con ciudadanos, empresas y otros grupos sociales, lo que se ha denominado gobierno electrónico (e-gobierno).1 El e-gobierno tiene como objetivo incrementar la eficiencia, la transparencia, la accesibilidad y la capacidad de respuesta a las demandas de los ciudadanos y organizaciones, así como lograr un gobierno competitivo que contribuya a alcanzar las metas de crecimiento económico y desarrollo social. El uso de las TIC's en el gobierno también tiene el potencial de transformar sus relaciones con los ciudadanos, las empresas y otras áreas del mismo gobierno (Banco Mundial, 2008; Gil-García y Helbig, 2006).

16 Artículo 261.- La denominación se formará libremente, pero distinta de la de cualquier otra sociedad.

17 ESCRITURA PÚBLICA, CONCEPTO DE.

18 Artículo 18 de la Ley.

19 Último párrafo del artículo 262 de la Ley General de Sociedades Mercantiles.

20 CORREDORES PÚBLICOS. LA FACULTAD PARA DAR FE DE LA DESIGNACIÓN DE REPRESENTANTES LEGALES DE SOCIEDADES MERCANTILES Y DE LAS FACULTADES DE QUE ESTÁN INVESTIDOS, NO EXCLUYE A LOS NOTARIOS PÚBLICOS DE ESA FUNCIÓN. 
modifica el concepto de fe pública como una atribución del estado y la función de los corredores públicos y notarios públicos a quienes se les otorga la misma por parte de éste, ${ }^{21}$ a nivel federal y estatal respectivamente

En cuanto al procedimiento de constitución de la SAS, el legislador prevé la intervención de la Administración Pública Federal primordialmente a través de varias entidades: la Secretaría de Economía (SEC), ${ }^{22}$ el Servicio de Administración Tributaria (SAT) ${ }^{23}$ y el Registro Público del Comercio ${ }^{24}$ (RPC) (Piña Mondragón, 2012). ${ }^{25}$

A fin de constituir una SAS, una vez cumplidos los requisitos que para los socios exige el artículo $262^{26}$ de la LGSM, la SEC abrirá un folio por cada sociedad que se constituya. El o los accionistas seleccionan las cláusulas de estatutos sociales que, de manera electrónica, pondrá a su disposición la SEC. Posteriormente se generará un contrato social que deberá ser firmado electrónicamente ${ }^{27}$ por los accionistas o accionista, según sea el caso, el cual será entregado de manera digital. La SEC verificará que el contrato social de la constitución de la sociedad cumpla con los requisitos específicos para los estatutos sociales al tenor de la LGSM, y de ser procedente lo enviará electrónicamente para su inscripción ${ }^{28} \mathrm{en}$

21 FE PÚBLICA. SU NATURALEZA JURÍDICA.

22 Secretaría de Economía.

23 Servicio de Administración Tributaria.

24 La publicidad de los actos de comercio es uno de los pilares fundamentales en que se sustenta el Derecho mercantil, derivada de la necesidad de proporcionar seguridad jurídica en cuanto a la existencia, capacidad y responsabilidad de los comerciantes, para su protección o la de terceros. En este sentido, dentro de las principales finalidades del Registro Público de Comercio, se encuentra la de dar publicidad de los actos mercantiles, de las personas, y de los documentos relacionados con ellos, y que conforme a la legislación, han de registrarse para surtir efectos contra terceros.

25 LA NATURALEZA JURÍDICA DEL REGISTRO PÚBLICO DE COMERCIO.

26 Artículo 262.- Para proceder a la constitución de una sociedad por acciones simplificada únicamente se requerirá: I. Que haya uno o más accionistas; II. Que el o los accionistas externen su consentimiento para constituir una sociedad por acciones simplificada bajo los estatutos sociales que la Secretaría de Economía ponga a disposición mediante el sistema electrónico de constitución; III. Que alguno de los accionistas cuente con la autorización para el uso de denominación emitida por la Secretaría de Economía, y IV. Que todos los accionistas cuenten con certificado de firma electrónica avanzada vigente reconocido en las reglas generales que emita la Secretaría de Economía conforme a lo dispuesto en el artículo 263 de esta Ley. En ningún caso se exigirá el requisito de escritura pública, póliza o cualquier otra formalidad adicional, para la constitución de la sociedad por acciones simplificada.

27 Mediante Firma Electrónica Avanzada.

28 Reglamento del Registro Público de Comercio. Artículo 1. - El presente ordenamiento establece las normas 
el Registro Público de Comercio. ${ }^{29}$ El RPC generará digitalmente la boleta de inscripción. Tanto el contrato social electrónico y la boleta digital del RPC prueban la existencia de la Sociedad por Acciones Simplificada.

En relación a la Sociedad por Acciones Simplificada, la SEC tiene específicamente las siguientes atribuciones:

\section{Emite la autorización de uso de denominación.}

2. Genera las reglas generales que reconocen la Firma Electrónica Avanzada; cuya obtención es un requisito que se exige a todos los accionistas para constituir este tipo de sociedad mercantil.

3. Está a cargo del Sistema Electrónico de Constitución de Sociedades por Acciones Simplificadas.

\section{Apertura un folio por cada SAS que se constituya.}

5. Pone a disposición de los accionistas modelos de cláusulas de Estatutos Sociales para el diseño de su Acta Constitutiva.

6. Verifica que el contrato social cumpla con todos los requisitos de constitución para la SAS que establece la LGSM. ${ }^{30}$

reglamentarias a que se sujetará la prestación del servicio del Registro Público de Comercio. Para efecto de este Reglamento se entiende por:

I. Secretaría: La Secretaría de Economía; II. Registro: El Registro Público de Comercio; III. SIGER: El Sistema Integral de Gestión Registral, y IV. Ley: La Ley General de Títulos y Operaciones de Crédito.

29 Artículo 2.- El Registro Público de Comercio tiene por objeto dar publicidad a los actos mercantiles, así como aquellos que se relacionan con los comerciantes y que conforme a la legislación lo requieran para surtir efectos contra terceros. Para la inscripción de los actos mercantiles que conforme a las leyes sean susceptibles de ello, se utilizarán las formas precodificadas que la Secretaría, en términos de lo dispuesto por el artículo 20 del Código de Comercio, dé a conocer mediante publicación en el Diario Oficial de la Federación. Los responsables de las oficinas del Registro, no podrán solicitar otros requisitos distintos a los que se incorporen en dichas formas. La inscripción de actos a que se refiere este artículo se efectuará en el folio mercantil electrónico, en atención al nombre, denominación o razón social de cada comerciante o sociedad mercantil, el cual comprenderá todos los actos mercantiles relacionados con dicho comerciante o sociedad.

30 Artículo 264 de la Ley General de Sociedades Mercantiles: Los estatutos sociales a que se refiere el artículo anterior únicamente deberán contener los siguientes requisitos: I. Denominación; II. Nombre de los accionistas; III. Domicilio de los accionistas; IV. Registro Federal de Contribuyentes de los accionistas; V. Correo electrónico de cada uno de los accionistas; VI. Domicilio de la sociedad; VII. Duración de la sociedad; VIII. La forma y términos en que los accionistas se obliguen a suscribir y pagar sus acciones; IX. El número, valor nominal y naturaleza de las acciones en que se divide el capital social; X. El número de votos que tendrá cada uno de los accionistas en virtud de sus acciones; XI. El objeto de la sociedad, y XII La forma de administración de la sociedad. 
7. Envía electrónicamente el contrato social de la SAS al Registro Público de Comercio para su inscripción,

8. Publica el factor de actualización en el Diario Oficial de la Federación en los términos del Código Fiscal de la Federación que sirve de base para determinar el tope de cinco millones de pesos como límite de ingresos totales anuales que permite a los socios de la SAS permanecer en este nuevo régimen; sin tener que transformarse de manera obligatoria a otra modalidad societaria. ${ }^{31}$

El Servicio de Administración Tributaria (SAT) interviene en la constitución de la Sociedad por Acciones Simplificada, al ser el único organismo de la Administración Pública Federal que emite la Firma Electrónica Avanzada(FIEL). ${ }^{32}$ Actualmente la FIEL es conocida como e.firma. La e.firma es un archivo digital que identifica al usuario al realizar trámites por internet en el SAT e incluso en otras dependencias del Gobierno de la República. ${ }^{33}$ La obtención de la e.firma requiere entre otras cosas para las personas físicas, de la Clave Única del Registro de Población (CURP) ${ }^{34}$ así como del Registro Federal de Contribuyentes (RFC). ${ }^{35}$ Estos elementos evidencian la estrecha relación que existe entre el procedimiento de constitución de la SAS y la fiscalización de los accionistas de dicha sociedad

31 Segundo párrafo del artículo 260 de la LGSM: Los ingresos totales anuales de una sociedad por acciones simplificada no podrá rebasar de 5 millones de pesos. En caso de rebasar el monto respectivo, la sociedad por acciones simplificada deberá transformarse en otro régimen societario contemplado en esta Ley, en los términos en que se establezca en las reglas señaladas en el artículo 263 de la misma.

32 El Poder Judicial de la Federación maneja su propia versión de firma electrónica denominada Firma Electrónica Certificada del Poder Judicial de la Federación (FIREL), utilizada conjuntamente con la FIEL emitida por el SAT, a través de las cuales es posible notificarse de las resoluciones jurisdiccionales emitidas por los Juzgados de Distrito y Tribunales de Circuito, así como el envío de demandas y promociones, todo a través de los recursos tecnológicos del Poder Judicial de la Federación. Poder Judicial de la Federación.

33 Cómo obtener tu e-firma.

34 La Clave Única de Registro de Población, mejor conocida como CURP, es un instrumento que sirve para registrar en forma individual a todos los habitantes de México, nacionales y extranjeros, así como a las mexicanas y mexicanos que radican en otros países

35 El Registro Federal de Contribuyentes, RFC es una clave que identifica como contribuyentes a las personas físicas o morales en México para controlar el pago de impuestos frente al SAT, el Servicio de Administración Tributaria. Sus siglas significan Registro Federal de Contribuyentes. Toda persona que realice alguna actividad económica que deba tributar impuestos deberá hacer su inscripción en el RFC SAT. CURP y RFC son unos de los documentos más importantes que puede tener un ciudadano mexicano. 
por parte del Servicio de Administración Tributaria.

La Secretaría de Economía, en coordinación con los Gobiernos de las 32 entidades federativas, operan el Registro Público de Comercio (RPC) por medio del Sistema Integral de Gestión Registral (SIGER), ${ }^{36}$ para modernizar y unificar la prestación del servicio. El SIGER garantiza la integridad de la información con el uso de la Firma Electrónica Avanzada, además de respaldarse en una Base de Datos Central. Permite las inscripciones y consultas por Internet, lo que lo convierte en una herramienta de vanguardia. ${ }^{37}$

El Registro Público de la Propiedad tiene las siguientes funciones respecto a la constitución de la SAS:

1.- Registra mediante el SIGER el contrato social que le envía la Secretaría de Economía.

2.- Emite la boleta de inscripción de la Sociedad por Acciones Simplificada.

La constitución y operación de la SAS se basa en dos sistemas:

Sistema Electrónico de Constitución (SECON) y;

Sistema de Información (SISIN)

Ambos sistemas son operados por la Secretaría de Economía. El SECON se utiliza en el procedimiento de constitución de la SAS, como se señaló en párrafos precedentes mientras que el SISIN es una herramienta contemplada en el artículo 89 del Código de Comercio, el cual es implementado por los accionistas en la operación de la SAS, específicamente en la celebración de Asambleas de Accionistas, así como en el ejercicio de sus derechos corporativos en el desarrollo de la misma. Para el caso que la SAS esté integrada por un solo socio, dicho accionista, él será el Órgano Supremo de la sociedad. Por disposición expresa del Código de Comercio, todas las publicaciones que deban realizarse al tenor de las leyes mercantiles en México, se realizarán a través del sistema electrónico que para tal propósito establezca la Secretaría de Economía. Una de las grandes

36 El SIGER también fue desarrollado para el registro de inmuebles, a fin de ayudar a los Gobiernos de los Estados, a favor de la seguridad jurídica.

37 Sistema Integral de Gestión Registral. 
innovaciones de la SAS, es la utilización de medios electrónicos tanto en la constitución y operación de la sociedad mercantil.

\section{Problemas jurídicos que implica la Reforma}

\subsection{La fe pública en el sistema legal mexicano}

El sistema jurídico mexicano pertenece a la familia neorromanista (Lan Arredondo A.J., 2011:26) que la integran los países cuya ciencia jurídica se ha elaborado sobre los fundamentos del derecho romano y de la tradición germánica, los cuales se fusionaron en el occidente de Europa a partir del siglo V (Sirvent Gutiérrez C., 2009: 08). La fuente primaria del derecho en México es la legislación y en segundo lugar la jurisprudencia que se define como un conjunto de principios establecidos en las resoluciones de determinados tribunales, al interpretar las leyes o al definir los casos no previstos en ellas. Los Jueces y los tribunales están obligados a resolver, de una u otra forma, los asuntos sometidos a su conocimiento, pero a veces es preciso averiguar el sentido que el legislador le quiso dar. ${ }^{38}$ De esta manera es la Suprema Corte de Justicia de la Nación, a través de sus Salas, y los Tribunales de Circuito quienes dan la interpretación final a los preceptos legales y conceptos jurídicos que no se encuentran definidos o cuya definición en las normas jurídicas es ambigua o incompleta.

Uno de estos conceptos jurídicos abstractos que no se encuentra definido en la legislación lo constituye la fe pública la cual ha sido precisada por los tribunales del Poder Judicial de la Federación como un atributo original del Estado, en virtud de su imperio, que se ejerce a través de los órganos estatales, pues por disposición de la ley los fedatarios la reciben mediante la patente respectiva, y aunque conforme al sistema jurídico mexicano no forman parte de la organización del Poder Ejecutivo sí son vigilados por éste. Así, por medio de la fe pública el Estado garantiza que son ciertos determinados hechos que interesan al derecho; de ahí que deba considerarse como la garantía de seguridad jurídica que da el fedatario tanto al Estado como al particular, ya que al determinar que

38 Sistema Jurídico Mexicano. 
un acto se otorgó conforme a derecho y que lo relacionado con él es cierto, contribuye al orden público, a la tranquilidad de la sociedad en que se actúa y a dar certeza jurídica. ${ }^{39}$

En el caso de la Sociedad por Acciones Simplificada, la reforma de la ley excluye expresamente en la etapa de constitución de la sociedad, la intervención de los fedatarios públicos que, en México la ejercen tanto los notarios públicos, que dan fe de actos jurídicos en general como los corredores públicos quienes otorgan fe pública sobre actos jurídicos en materia mercantil atento a lo que dispone la Ley Federal de Correduría Pública. ${ }^{40}$

La reforma a la Ley General de Sociedades Mercantiles que crea la Sociedad por Acciones Simplificada, específicamente en el artículo 262 último párrafo textualmente establece así: "En ningún caso se exigirá el requisito de escritura pública, póliza o cualquier otra formalidad adicional, para la constitución de la sociedad por acciones simplificada.". Del texto de este artículo se desprende que, en el proceso de constitución de la SAS, se excluye expresamente, la intervención de fedatarios públicos, (corredores públicos y notarios públicos), lo que rompe con el paradigma de la seguridad jurídica y certeza que la fe pública otorga.

Así es, el estado mexicano concede fe pública a notarios públicos y corredores públicos para que éstos, a través de sus escrituras públicas y pólizas, hagan constar la existencia de los actos jurídicos, de naturaleza civil o mercantil. La fe pública que otorgan los fedatarios públicos sobre los actos jurídicos de cualquier naturaleza, demuestra las garantías de legalidad y seguridad jurídica contenidas en los artículos 14,16 y 17 constitucionales. A partir de las reformas a la Constitución Política de los Estados Unidos Mexicanos de junio de 2011 estas garantías se elevan a la categoría de derechos humanos. Por lo tanto, el otorgamiento de la fe pública por parte de personas físicas a nivel estatal, notarios públicos de acuerdo a los ordenamientos y procedimientos establecidos en la legislación local y corredores públicos a nivel federal constituyen derechos humanos.

39 FE PÚBLICA, SU NATURALEZA JURÍDICA.

40 ARTICULO 6o.- Al corredor público corresponde: I, II, III, IV, V,VI. Actuar como fedatario en la constitución y en los demás actos previstos por la Ley General de Sociedades Mercantiles incluso aquellos en los que se haga constar la representación orgánica; 
El tercer párrafo del artículo 1 de la Constitución Política de los Estados Unidos Mexicanos, contenido en el Título I de la misma que se denomina "De los Derechos Humanos y sus Garantías" establece que: "Todas las autoridades, en el ámbito de sus competencias, tienen la obligación de promover, respetar, proteger y garantizar los derechos humanos de conformidad con los principios de universalidad, interdependencia, indivisibilidad y progresividad. En consecuencia, el Estado deberá prevenir, investigar, sancionar y reparar las violaciones a los derechos humanos, en los términos que establezca la ley."

\subsection{La implementación electrónica de la Sociedad por Acciones Simplificada viola los derechos humanos de seguridad y legalidad jurídica contenidos en la Constitución Política de los Estados Unidos Mexicanos}

En el caso de la Sociedad por Acciones Simplificada, la reforma que la crea y que excluye en la constitución de la misma a los fedatarios públicos (notarios y corredores), viola los derechos humanos de seguridad y legalidad tanto de los fedatarios como de los futuros socios, tanto personas físicas como jurídicas, nacionales o extranjeras porque los priva de la certeza y seguridad jurídica de la que está revestida la fe pública como potestad del Estado que la delega en los multicitados notarios públicos y corredores públicos. La fe pública no puede ser sustituida por una firma electrónica avanzada ni por una plataforma digital o cualquier método sistematizado por el estado para suplir precisamente su poder de imperio para dar fe y legalidad a los actos jurídicos celebrados al tenor de las leyes que constituyen el ordenamiento jurídico nacional.

La Suprema Corte de Justicia de la Nación ha determinado en jurisprudencia vigente que: "Los actos de autoridad de creación y vigencia de normas generales pueden combatirse en el juicio de garantías, con base en la infracción de exigencias que deben respetar, como las derivadas del proceso legislativo establecidas en la Constitución Política de los Estados Unidos Mexicanos, o incluso aquellas derivadas del respeto a la garantía de seguridad jurídica que comprende las denominadas sub-garantías de legalidad, fundamentación, motivación, competencia, irretroactividad y audiencia, cuya violación puede demostrarse no sólo a través de la exposición de una contradicción directa con el texto fundamental, sino mediante las incongruencias en el orden jurídico que revelen 
transgresión a esa garantía, como la contradicción entre normas secundarias, lo que implica vulneración indirecta al texto constitucional, sin embargo, en este último supuesto, el examen de las normas jurídicas relativas debe sustentarse no únicamente en afirmaciones tocantes a la incongruencia entre leyes secundarias, sino también en la precisión de las garantías individuales violadas, y en la demostración de que la norma aplicada es la que viola el orden constitucional y no exclusivamente el ordenamiento jurídico utilizado como parámetro comparativo para derivar la incongruencia o carencia de facultades, pues sólo de esa manera se podría demostrar que se aplicó en el acto reclamado una ley inconstitucional, de otra manera, por más inconstitucional que resultara la norma comparativa no aplicada, no podría concederse la protección federal." ${ }^{41}$ Achtung: asunto plaza UdG.

En el caso concreto de la Sociedad por Acciones simplificada, existe contradicción e incongruencia entre la Ley General de Sociedades Mercantiles que la crea en cuanto a los requisitos de constitución, el Código Civil Federal que suple las deficiencias y lagunas de este ordenamiento y la Ley Federal de Correduría Pública que establece el carácter de fedatario público de los corredores públicos. También existe contradicción e incongruencia entre el texto de la reforma en cuanto a la creación de la sociedad y los ordenamientos estatales que establecen el carácter de fedatarios de los notarios públicos, que, por disposición expresa de la ley, otorgan fe pública a los actos jurídicos que se celebran ante ellos. Los actos jurídicos en los que intervienen los notarios públicos constan en las escrituras públicas que elaboran y los actos jurídicos en los que intervienen los corredores públicos en las pólizas que redactan.

La contradicción e incongruencia entre la reforma que crea la SAS y los ordenamientos secundarios señalados estriban en que por regla general la constitución de sociedades mercantiles en México requiere de la fe pública de los fedatarios públicos a fin de dar certeza y seguridad precisamente en el acto mismo de constitución de la sociedad mercantil con la intervención de fedatarios públicos y en el caso de la Sociedad por Acciones Simplificada, se omite la

41 AMPARO CONTRA LEYES. LA INCONSTITUCIONALIDAD DE ÉSTAS PUEDE DERIVAR DE LA CONTRADICCIÓN CON OTRAS DE IGUAL JERARQUÍA, CUANDO SE DEMUESTRE VIOLACIÓN A LA GARANTÍA DE SEGURIDAD JURÍDICA. 
fe pública del estado sustituyéndola por la utilización de la Firma Electrónica Avanzada, que constituye un medio para autenticar al titular esencialmente para fines de declaración de impuestos a través de dispositivos electrónicos. El utilizar estos dispositivos para realizar pagos de impuestos vía internet, significa que es usado por una persona física que no necesariamente sea el titular de la misma porque en razón de la confianza o a veces por un delito, se puede tener acceso a los mismos y a las claves que permiten ingresar a los diversos sistemas electrónicos gubernamentales que requieren el uso de la firma electrónica avanzada para diversos trámites en los portales de la administración pública.

\subsection{Violación al principio de progresividad de los derechos humanos}

La ausencia de fe pública en el procedimiento electrónico de constitución de la Sociedad Simplificada por Acciones, viola el principio de progresividad de los derechos humanos contenido en el artículo 1 de la Constitución Política de los Estados Unidos Mexicanos, de los cuales son titulares tanto las personas físicas como jurídicas. ${ }^{42}$ Este principio es definido precisamente por la Suprema Corte de Justicia de la Nación en base a la jurisprudencia internacional de derechos humanos en los siguientes términos: "progresividad: constituye el compromiso de los Estados para adoptar providencias, tanto a nivel interno como mediante la cooperación internacional, especialmente económica y técnica, para lograr progresivamente la plena efectividad de los derechos que se derivan de las normas económicas, sociales y sobre educación, ciencia y cultura, principio que no puede entenderse en el sentido de que los gobiernos no tengan la obligación inmediata de empeñarse por lograr la realización íntegra de tales derechos, sino en la posibilidad de ir avanzando gradual y constantemente hacia su más completa realización, en función de sus recursos materiales; así, este principio exige que a medida que mejora el nivel de desarrollo de un Estado, mejore el nivel de compromiso de garantizar los derechos económicos, sociales y culturales." ${ }^{43}$

\footnotetext{
42 CONTROL DE CONVENCIONALIDAD EX OFFICIO. DEBE ORIENTARSE A LA TUTELA DE LAS PERSONAS JURÍDICAS, CUANDO SE PROTEJAN LOS DERECHOS Y LIBERTADES DE ACCESO A LA JUSTICIA, SEGURIDAD JURÍDICA Y LEGALIDAD DE SUS SOCIOS, INTEGRANTES O ACCIONISTAS.

43 PRINCIPIOS DE UNIVERSALIDAD, INTERDEPENDENCIA, INDIVISIBILIDAD Y PROGRESIVIDAD DE LOS DERECHOS HUMANOS. EN QUÉ CONSISTEN.
} 
En el caso específico de la Sociedad por Acciones Simplificada, se viola el principio de progresividad porque la ausencia de fe pública en la etapa de constitución de la sociedad mercantil de referencia, constituye un retroceso en la implementación de normas jurídicas que garanticen seguridad jurídica en este caso a los inversionistas nacionales y extranjeros, sean personas físicas o jurídicas, puesto que la constitución electrónica de la SAS mediante una plataforma operada por la Secretaría de Economía en coordinación con el Registro Público de Comercio no garantiza la certeza y seguridad jurídica a las personas físicas y jurídicas, a pesar que se utilice un dispositivo electrónico para generar una Firma Electrónica Avanzada, la cual no sustituye a la fe pública del estado.

En relación a los tratados bilaterales y multilaterales de comercio e inversión que tiene celebrado el estado mexicano con otros países se evidencia la violación del principio de progresividad con la reforma que crea la Sociedad por Acciones Simplificada sin la intervención de fedatarios públicos en su etapa de constitución porque al no existir la fe pública del estado en la creación de esta sociedad, no se otorga certidumbre a los flujos de capital y no se garantiza seguridad jurídica a los inversionistas nacionales y extranjeros, lo anterior en contravención a los capítulos de inversión de los multicitados tratados.

\section{Conclusiones}

A fin de garantizar certeza y seguridad jurídica al socio o socios de este régimen en México bajo el nuevo esquema de Sociedad por Acciones Simplificada es necesario que el poder legislativo en México, a través del Congreso de la Unión, modifique mediante la iniciativa correspondiente, los artículos que establecen este novedoso sistema societario de manera que el estado otorgue fe pública a través de fedatarios públicos al acto de constitución de la sociedad.

Lo anterior no implica modificar el esquema de constitución de dicha sociedad prescindiendo del uso de la Firma Electrónica Avanzada, al contrario, la utilización de dicho dispositivo, junto con el Registro Público de Comercio mediante el Sistema Integral de Gestión Registral (SIGER) complementa la 
efectividad de la fe pública del estado para corroborar la existencia de los actos jurídicos mediante de la intervención de los fedatarios públicos en los términos que la legislación civil y mercantil establece.

\section{Bibliografía}

\section{Libros:}

Castrillón Luna, Víctor M. (2010) Ley General de Sociedades Mercantiles Comentada, Quinta Edición, México, Porrúa.

Lan Arredondo A.J. (2011). Sistemas Jurídicos. México: Oxford Colección Textos Jurídicos Universitarios.

Sirvent Gutiérrez C. (2009). Sistemas Jurídicos Contemporáneos. 11ª Ed. México: Editorial Porrúa. p.8.

Trueba Urbina Alberto, Jorge Trueba Barrera (2004) Ley Federal del Trabajo, Comentarios, Prontuario, Jurisprudencia y Bibliografía, 85 Edición Actualizada, México, Editorial Porrúa.

\section{Documentos digitales:}

Springer Link Entrepeneurship in Mexico < http://link.springer.com/ch apter/10.1057/9781137003324_7\#page-2>(Fecha de consulta: 5 de julio de 2016).

Secretaría de Economía Fondo Pyme $<$ http://www.fondopyme.gob.mx/ $>$ $>$ (Fecha de consulta: 5 de julio de 2016).

Pro México Pymes Eslabón fundamental para el crecimiento en México. http://www.promexico.gob.mx/negocios-internacionales/pymeseslabon-fundamental-para-el-crecimiento-en-mexico.html $>$ (Fecha de consulta: 5 de julio de 2016).

El Economista México, ejemplo de simplificación administrativa: 
BM. <http://eleconomista.com.mx/sistema-financiero/2010/03/03/ mexico-ejemplo-simplificacion-administrativa-bm $>$ (Fecha de consulta: 6 de julio de 2016).

Organización para la Cooperación y el Desarrollo Económico. Facilidad y rapidez en la creación de empresas en Méxicohttps://www.oecd. org/centrodemexico/medios/43843217.pdf (Fecha de consulta: 5 de julio de 2016).

Embajada de Japón Año del Intercambio México-Japón 2013-2014 400 aniversario de la misión Hasekura http://www.mx.emb-japan.go.jp/ hasekura/sp/index.html $>$ (Fecha de consulta: 12 de julio de 2016).

Melba Falck Reyes Debate Social El Acuerdo de Asociación Económica entre México y Japón, ¿ha sido beneficioso para México? $<$ https:// blogs.iteso.mx/debatesocial/2015/07/13/el-acuerdo-de-asociacioneconomica-entre-mexico-y-japon-ha-sido-beneficioso-para-mexicomelba-falck-reyes/> (Fecha de consulta: 12 de julio de 2016).

Héctor Palacios México y la cuenca del Pacifico <http://www. mexicoylacuencadelpacifico.cucsh.udg.mx/sites/default/ files/Jap \%C3\%B3 n \% 20y\%2 0 M\%C3\% A 9x ico\%20-\%20 E1\%20inicio\%20de\%20sus\%20relaciones\%20y\%201a\%20 inmigraci $\% \mathrm{C} 3 \% \mathrm{~B} 3 \mathrm{n} \% 20 \mathrm{japonesa} \% 20$ durante $\% 20 \mathrm{el} \% 20$ Porfiriato. pdf $>$ (Fecha de consulta: 15 de julio de 2016).

Organización de Estados Americanos <http://www.sice.oas.org/Trade/ MEX_JPN_s/JPN_MEX_s.asp\#Art\%C3\%ADculo_1 $>>($ Fecha de consulta: 12 de julio de 2016).

International Monetary Fund <https://www.imf.org/external/pubs/ft/ weo/2016/01/pdf/statapp.pdf $>$ (Fecha de consulta: 12 de julio de 2016).

El Economista. <http://eleconomista.com.mx/industrias/2015/02/19/ cumple-10-anos-asociacion-economica-mexico-japon $>$ (Fecha de consulta: 12 de julio de 2016).

Librería Cide < http://www.libreriacide.com/librospdf/DTAP-214. pdf $>$ (Fecha de consulta: 17 de julio de 2016).

Cámara de Diputados H. Congreso de la Unión $<$ http://www.diputados. 
gob.mx/LeyesBiblio/index.htm $>$ (Fecha de consulta: 12 de julio de 2016).

Secretaría de Economía < http://www.gob.mx/se/>(Fecha de consulta:

12 de julio de 2016).

Servicio de Administración Tributaria $<\mathrm{http}$ //www.sat.gob.mx/Paginas/

Inicio.asp $x>$ (Fecha de consulta: 12 de julio de 2016).

Semanario Judicial de la Federación <http://sjf.scjn.gob.mx/SJFSem/

Paginas/SemanarioIndex.asp $x>$ (Fecha de consulta: 12 de julio de 2016).

José Joaquín Piña Mondragón. $>$ http://www.juridicas.unam.mx/publica/

librev/rev/facdermx/cont/258/art/art20.pdf $>$ (Fecha de consulta: 12 de julio de 2016).

Poder Judicial de la Federación <https://www.pjf.gob.mx/> (Fecha de consulta: 12 de julio de 2016).

Secretaría de Gobernación <http://www.gob.mx/segob> (Fecha de consulta: 12 de julio de 2016).

Sistema Integral de Gestión Registral < http://www.siger.gob.mx/>

(Fecha de consulta: 26 de julio de 2016).

Suprema Corte de Justicia de la Nación <https://www.scjn.gob.mx/ conocelacorte/documents/publicaciones/sistema-juridico-mexicano. pdf $>$ (Fecha de consulta: 18 de septiembre de 2016).

Sistema de Información sobre Comercio Exterior

$<$ http://www.sice.oas.org/countries_s.asp $>$ (Fecha de consulta: 4 de diciembre de 2016).

Cámara de Diputados

$<$ http://www.diputados.gob.mx/> (Fecha de consulta: 4 de diciembre de 2016). 